\title{
Adaptação de usina para reciclagem à quente e avaliação laboratorial das misturas asfálticas produzidas
}

A utilização de misturas asfálticas recicladas demonstra-se viável técnica e ambientalmente, além de possibilitar a redução de custos. Desta forma, esta pesquisa buscou elaborar projetos contendo 10 (M10), 20 (M20) e 30\% (M30) de material fresado (RAP), implementar usina volumétrica incorporando RAP a frio no misturador, avaliar laboratorialmente as misturas produzidas e verificar a viabilidade financeira. Enquadrou-se a granulometria dos projetos na Especificação de Serviço 031/2006 do DNIT, utilizando-se CAP 60/85 (modificado por polímero do tipo SBS), agregado granítico e RAP com agregado de origem basáltica com CAP, também, modificado por polímero. Verificou-se, após a usinagem, comportamento semelhante ao projetado. O ensaio de Módulo de Resiliência demonstrou um aumento de rigidez com a inserção de RAP. Através do Módulo Complexo não se pode atribuir comportamento elástico ou viscoso ao percentual de RAP inserido. No ensaio de Resistência a Tração por Compressão Diametral, notou-se um aumento de resistência nas misturas com o incremento de percentual de RAP, entretanto, para o Flow Number, avaliando-se a resistência a deformação permanente, os valores diminuíram. Nas verificações de Dano por Umidade Induzida e Desgaste Cântabro não se verificou um comportamento específico de acordo com a incorporação de fresado, mas as misturas recicladas obtiveram resultados semelhantes à convencional. Avaliou-se a M10, na Fadiga, através do ensaio de Tração-Compressão, como o melhor comportamento e, a M30, o pior. Ainda, verificou-se que o custo da M10, durante a vida de fadiga, é expressivamente menor comparando-o às outras misturas, mas, na oportunidade de uso, há de se considerar a escolha da M20, visto a viabilidade financeira e maior impacto ambiental positivo, bem como as características

\section{Plant adaptation for hot recycling and laboratory evaluation of asphaltic mixtures produced}

\begin{abstract}
The use of recycled asphalt mixtures is technically and environmentally feasible, in addition to enabling cost reduction. Therefore, the next time you buy material containing 10 (M10), 20 (M20) and 30\% (M30) of milled material (RAP), implement volumetric plants incorporating cold RAP without rinsing, laboratory evaluation as mixtures produced and verify financial viability. The granulometry of the projects was classified in the Service Specification 031/2006 of DNIT, using CAP 60/85 (modified by polymer of type SBS), granitic aggregate and RAP with aggregate of basaltic origin with CAP, also, modified by polymer. After machining, the behavior when designing was verified. The resilient modulus assay demonstrated increased stiffness with a RAP insert. Through the Complex Module, elastic or viscous behavior cannot be applied to the percentage of RAP inserted. In the Tensile Strength, an increase in strength was noted in the mixtures insert. Through the Complex Module, elastic or viscous behavior cannot be applied to the percentage of RAP inserted. In the Tensile Strength, an increase in strength was noted in the mixtures
with the addition in percentage of RAP, however, for the Flow Number, evaluating the resistance to permanent deformation, the values decreased. In the verifications of Damage by Induced Moisture and Cantabro abrasion, there was no specific behavior according to the milling incorporation, but as recycled blends, the results seem conventional. The M10, in Fatigue, was evaluated through the Traction-Compression test, as the best behavior and, the M30, the worst. Still, it was found that the cost of M10, during the life of fatigue, is significantly lower when compared to other mixtures, but, in the opportunity of use, it is necessary to consider the choice of M20, given the financial viability and greater impact positive environmental impact, as well as similar mechanical characteristics, in relation to M10. There is a possibility of using hot recycling.
\end{abstract}

Keywords: Milling Material; Recycling of Pavements; Hot recycled asphalt mixtures.

Felipe Cipriani Luzzi (D)

Universidade Federal de Santa Maria, Brasi http://lattes.cnpq.br/9007262951949197 http://orcid.org/0000-0002-6110-4570 fcluzzi@gmail.com

Luciano Pivoto Specht (iD)

Universidade Federal de Santa Maria, Brasi http://lattes.cnpq.br/8038412953408618 http://orcid.org/0000-0002-8709-6273

luspecht@ufsm.br

Silvio Lisboa Schuster (iD

Universidade Federal de Santa Maria, Brasil http://lattes.cnpq.br/3709183577250865 http://orcid.org/0000-0003-2269-7788 silviolschuster@gmail.com
Fernando Dekeper Boeira (D)

Universidade Federal de Santa Maria, Brasil http://lattes.cnpq.br/6115383054055572 http://orcid.org/0000-0003-0277-4686 fernando.d.boeira@gmail.com

Deividi da Silva Pereira (iD

Universidade Federal de Santa Maria, Brasil http://lattes.cnpq.br/9639329922610388 http://orcid.org/0000-0002-7200-7813 dsp@ufsm.br

Pedro Orlando Borges de Almeida Júnior (iD) Universidade Federal de Santa Maria, Brasil http://lattes.cnpq.br/3229920135442077 http://orcid.org/0000-0002-8428-5853

engcivilpedro@hotmail.com
Thiago Vitorello (iD

Universidade Federal do Rio Grande do Sul, Brasil http://lattes.cnpq.br/8634193908941203 http://orcid.org/0000-0002-3922-4568 thiago.vitorello@triunfoconcepa.com.br

\section{Fábio Hirsch (iD)}

Universidade Federal do Rio de Janeiro, Brasil http://lattes.cnpq.br/3284823721153425 http://orcid.org/0000-0001-9213-9736 fabio.hirsch@triunfoconcepa.com.br

DOI: 10.6008/CBPC2179-6858.2021.003.0030

\section{Referencing this:}

LUZZI, F. C.; SPECHT, L. P.; SCHUSTER, S. L.; BOEIRA, F. D.; PEREIRA, D. S.; ALMEIDA JÚNIOR, P. O. B.; VITORELLO, T.; HIRSCH, F.. Adaptação de usina para reciclagem à quente e avaliação laboratorial das misturas asfálticas produzidas. Revista Ibero Americana de Ciências Ambientais, v.12, n.3, p.362-382, 2021. DOI: http://doi.org/10.6008/CBPC2179-6858.2021.003.0030 


\section{INTRODUÇÃO}

De modo geral, os pavimentos asfálticos brasileiros vêm apresentando deficiências funcionais e estruturais, assim, a necessidade de conservação rotineira se torna indispensável para a manutenção do pavimento e da garantia da segurança e conforto aos usuários. Ademais, a precariedade da malha rodoviária aliada ao pouco recurso financeiro despendido levanta a possibilidade de soluções alternativas de manutenção e construção de novos pavimentos.

A Confederação Nacional do Transporte (CNT, 2018), em uma análise histórica de 2004 a 2018, avaliou $100 \%$ das rodovias federais brasileiras e constatou que estas melhoraram em 23 pontos percentuais, saindo de 18,7\% com classificação ótimo ou bom, em 2004, para 41,6\%, em 2018. Mesmo com esta ascensão, 48,5\% das rodovias não apresentam condições adequadas e, em 2018, cerca de 32 mil quilômetros ainda apresentavam deficiências no pavimento, na sinalização e na geometria. Rocha et al. (2016) relata que não será possível superar as carências no Brasil, em infraestrutura viária, e é muito difícil atender a toda a demanda existente de novas construções, sem considerar o uso racional de materiais reciclados.

A promoção do uso de fontes energéticas renováveis, reforma de setores de energia e transportes, limitação de emissões de gases poluentes e a proteção do meio ambiente em geral são políticas adotadas no Protocolo de Kyoto (1997) e reafirmadas no Acordo de Paris (2015), as quais, direcionam os setores produtivos dos principais países ao redor do mundo a manter a sustentabilidade ambiental para estas e próximas gerações. Alinhado a esta preocupação com os danos causados ao meio ambiente, o setor da pavimentação avança tecnologicamente destacando-se em pesquisas relacionadas à redução ou mitigação destes impactos.

A engenharia busca soluções para a redução do consumo de insumos na pavimentação, com critérios técnicos necessários, controle de custos e políticas de sustentabilidade viáveis. Deste modo, surgem alternativas com a possibilidade de abranger todas as necessidades na construção, manutenção e operação de rodovias. A reciclagem de pavimentos é evidenciada pela possibilidade de aliar a redução de custos, impactos nocivos e manutenção da qualidade. Esta técnica consiste na reutilização de material fresado (do inglês - Reclaimed Asphalt Pavement - RAP), originário, geralmente, de serviços de conservação e manutenção de revestimentos, em novas camadas do pavimento.

No exterior, o foco das pesquisas e da indústria tem sido colocar uma maior quantidade de RAP nas novas misturas (HUANG et al., 2005). O teor incorporado cerca os $40 \%$ já sendo considerado alto, pois ainda existem barreiras técnicas a serem vencidas, principalmente ligadas ao aquecimento do RAP e a ativação do ligante antigo. Por outro lado, a necessidade da reutilização destes materiais e a busca ininterrupta por inovações tecnológicas, traz ao setor, beneficiadores e usinas capazes de reciclar por completo o material fresado, como em casos na Europa e nos EUA que já chegam a 100\% (ZAUMANIS et al., 2014).

No Brasil existe um grande distanciamento da prática internacional (considerando países desenvolvidos) visto que são raras as aplicações de reciclagem à quente no país. Neste contexto, esta pesquisa buscou elaborar projetos contendo 10 (M10), 20 (M20) e 30\% (M30) de material fresado (RAP), 
implementar usina volumétrica incorporando RAP a frio no misturador, avaliar laboratorialmente as misturas produzidas e verificar a viabilidade financeira.

\section{REVISÃO TEÓRICA}

\section{Reciclagem à quente em usina}

As misturas asfálticas recicladas à quente em usinas podem ser produzidas tanto em centrais gravimétricas (por batelada) quanto em volumétricas (contínuas) (ARRA, 1997). A porcentagem em peso de material fresado a ser inserido na mistura está diretamente ligada à tecnologia do processo de inserção de RAP na usina, o qual se define pelo tipo de transferência de calor recebido durante o processo de mistura (SUZUKI, 2019). A Figura 1 ilustra um exemplo de usina para reciclagem de misturas asfálticas à quente.

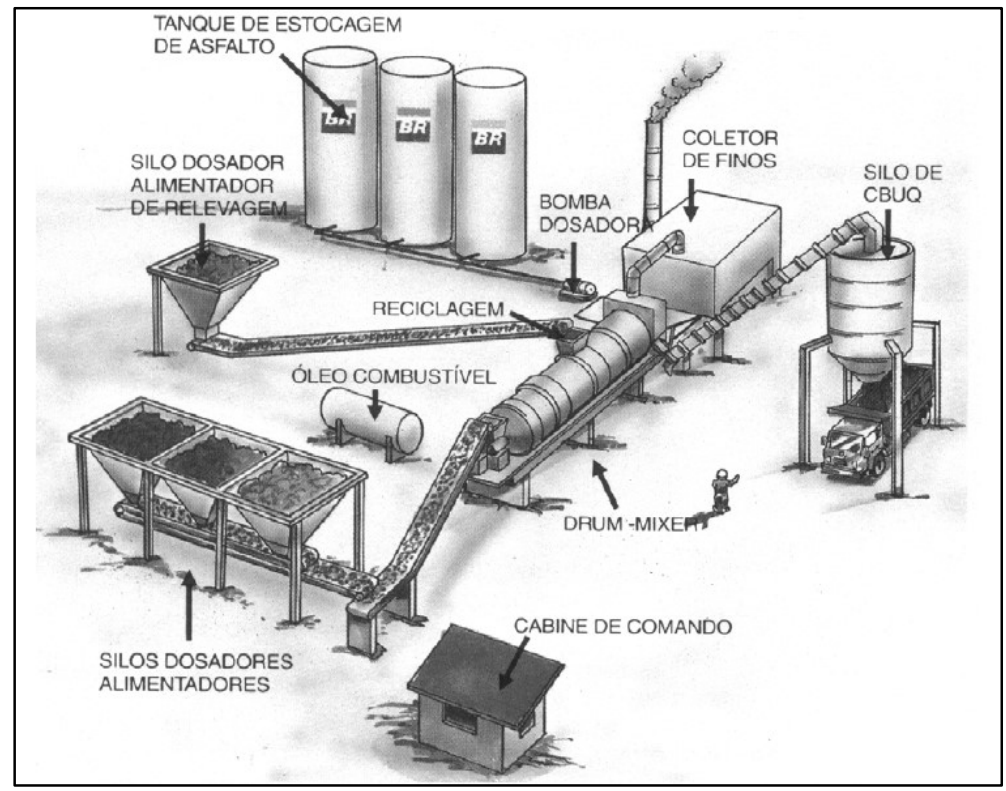

Figura 1: Croqui de usina para reciclagem à quente.

Segundo NAPA (1996), os principais tipos de transferência de calor podem ser descritos como: por condução, quando materiais se tocam e por convecção, onde partículas sólidas são expostas a correntes de gases quentes. Dependendo do método de transferência de calor e percentual de RAP pretendido, mais detalhada deve ser a implementação da usina. A exposição do RAP a altas temperaturas e/ou a chama direta do secador podem ocasionar danos à estrutura da mistura.

As usinas devem garantir precisão quando da incorporação de RAP nas misturas asfálticas. No sistema de entrada de RAP realizada a frio nas usinas, quando é necessário o superaquecimento de agregados virgens como processo de transferência de calor, é fundamental que RAP e agregados tenham um baixo teor de umidade (FHWA, 2011).

A capacidade produtiva bem como a qualidade do produto final das misturas recicladas à quente passa pela qualidade da gestão e beneficiamento do estoque de RAP a utilizar, devendo este ser tratado como um material nobre. A gestão ineficiente das pilhas de RAP é uma das principais razões pelas quais os órgãos reguladores ainda são resistentes com o aumento de percentuais a serem incorporados nas misturas. 
Alguns órgãos reguladores dos EUA, permitem apenas RAP de projetos conhecidos e de autoria do próprio órgão. Estes fresados de projetos das próprias agências são denominados de "RAPs classificados", enquanto, os de natureza não totalmente conhecida são chamados de RAPs "não classificados" (WEST, 2010; ZUBARAN, 2014).

De acordo com West et al. (2009), um fator importante para o aumento de taxa de incorporação de RAP em misturas asfálticas é o percentual de agregado miúdo contido no material fresado. Uma forma eficaz de beneficiamento do RAP é o seu destorroamento e peneiramento. Este fracionamento, geralmente, é realizado em duas ou três peneiras, o que flexibiliza o enquadramento deste material nas especificações dos órgãos rodoviários.

Algumas vantagens podem ser destacadas na reciclagem à quente em usinas quando comparadas aos outros métodos de reciclagem, entre elas estão o reaproveitamento tanto dos agregados quanto do ligante asfáltico do RAP, a correção de possíveis erros de dosagem do projeto inicial da mistura, a reciclagem da espessura total da camada de revestimento e a possibilidade de análise laboratorial dos materiais após remoção da camada (SUZUKI, 2019).

\section{METODOLOGIA}

Esta pesquisa consistiu na elaboração de um projeto de concreto asfáltico convencional e mais três misturas asfálticas recicladas à quente com a incorporação de 10, 20 e 30\%, em massa, de material fresado. A adaptação de uma usina volumétrica em campo foi necessária para a produção em escala real destas misturas. Analisou-se as características da usinagem e gestão dos materiais e procedimentos, bem como ensaios laboratoriais dos materiais produzidos. Os agregados utilizados nesta pesquisa são de origem granítica de unidade de britagem do Município de Eldorado do Sul/RS, onde também está localizada a usina. O ligante asfáltico é modificado por polímero SBS do tipo 60/85. Para a composição das misturas foram utilizadas as frações de agregados, 3/4", 3/8" e pó-de-pedra. O material fresado foi coletado a partir dos serviços de conservação e manutenção de pavimentos da rodovia BR-290/RS e BR-116/RS, entre os municípios de Guaíba e Osório/RS. A caracterização do RAP encontra-se na Tabela 1.

Tabela 1: Teor de ligante, de umidade e massa específica máxima medida do RAP.

\begin{tabular}{lllllll}
\hline Ensaio & Am1 & Am2 & Am3 & Am4 & Média & Desv. Pad \\
\hline Teor de Ligante & $5,13 \%$ & $4,81 \%$ & $5,10 \%$ & $4,75 \%$ & $4,95 \%$ & $0,20 \%$ \\
Teor de umidade & $4,44 \%$ & $4,23 \%$ & $4,60 \%$ & $4,30 \%$ & $4,39 \%$ & $0,16 \%$ \\
Gmm & 2,536 & 2,545 & 2,543 & 2,552 & 2,544 & 0,007 \\
\hline
\end{tabular}

Tabela 2: Características do ligante do RAP após extração pelo método Abson.

\begin{tabular}{lllll}
\hline Ensaios & Referência & Amostra 1 & Amostra 2 & Média \\
\hline Recuperação Elástica & $>68$ & 40 & 38 & 39 \\
Ponto de Amolecimento & 55 a 67 & 62 & 79 & 70,5 \\
Penetração a $25^{\circ} \mathrm{C}$ & 24 a 42 & 26 & 12 & 19 \\
Teor de CAP & -- & 5,0 & 4,2 & 4,6 \\
Viscosidade Brookfield $135^{\circ} \mathrm{C}$ & $<3000$ & 1481 & 5706 & 3593,5 \\
Viscosidade Brookfield $150^{\circ} \mathrm{C}$ & $<2000$ & 648 & 2057 & 1352,5 \\
Viscosidade Brookfield $177^{\circ} \mathrm{C}$ & $<1000$ & 201 & 548 & 374,5 \\
\hline
\end{tabular}


Para verificar o tipo de ligante presente no RAP, foi realizada, em duas das amostras recolhidas, a extração de ligante pelo método Abson e os resultados dos ensaios de recuperação elástica a $25^{\circ} \mathrm{C}$, ponto de amolecimento, penetração a $25^{\circ} \mathrm{C}$, viscosidade Brookfield, encontram-se resumidos na Tabela 2.

Verifica-se, a partir dos dados relacionados na Tabela 2, que as amostras de RAP coletadas são de misturas asfálticas que se utilizavam de ligante asfáltico com polímero em sua composição, de acordo com dados de ponto de amolecimento, penetração, viscosidade e recuperação elástica, os quais, mesmo que um pouco abaixo dos valores de referência. Ressalta-se que nos últimos anos, a concessionária administradora da rodovia utilizava apenas soluções em concreto asfáltico com ligante modificado por polímero, corroborando com os resultados encontrados nos ensaios.

A partir das granulometrias definidas dos agregados e RAP, as curvas das misturas asfálticas foram definidas respeitando a faixa C (DNIT ES 31/2006) e as suas respectivas tolerâncias. Respeitando as condicionantes impostas pela usina de asfalto, pelo processo de incorporação de RAP proposto, o limitante de quantidade de RAP a utilizar nos projetos foi de 30\%, em massa. Partindo-se da melhor adequação da curva ao centro da especificação da norma supracitada, os projetos estão apresentados na Figura 2.

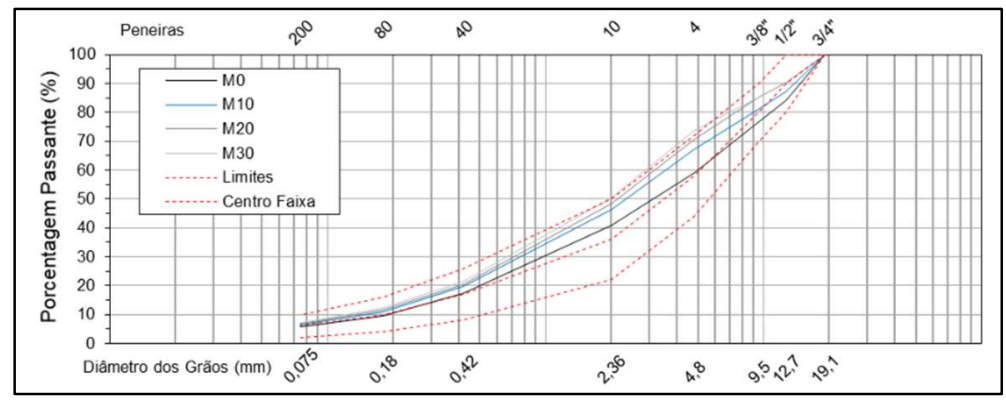

Figura 2: Composição das curvas granulométricas definidas.

Através do método Marshall (DNER ME 43/95, moldagem de corpos de prova com 10cm de diâmetro e 6,35 $\pm 1,5 \mathrm{~cm}$ de altura com a aplicação de 75 golpes por face), procurou-se buscar o teor de ligante asfáltico de projeto para cada uma das misturas o mais próximo possível do centro da ES-31/2006, em 4\% de volume de vazios, avaliando-se as curvas encontradas e o histórico de utilização de misturas asfálticas para os agregados e ligante utilizados. Verifica-se que os teores de projeto reduziram proporcionalmente com o maior percentual de incorporação de material fresado nas misturas, o que era esperado, conforme descrito em Centofante (2018) e Bohn (2020). Na Tabela 3 estão os dados resumidos dos projetos elaborados.

Tabela 3: Resumo dos dados de projetos.

\begin{tabular}{llllll}
\hline Dados Projeto & DNIT - ES 031/2006 & M0 & M10 & M20 & M30 \\
\hline Teor de Betume a adicionar (\%): & -- & 5,65 & 5,30 & 4,85 & 3,87 \\
Teor de Betume total (\%): & -- & 5,65 & 5,58 & 5,51 & 5,44 \\
Adição de RAP (\%): & & 0 & 10 & 20 & 30 \\
Volume de Vazios (\%): & 3 a 5 & 4,01 & 3,96 & 4,11 & 4,05 \\
RBV (\%): & 75 a 82 & 76,51 & 75,27 & 72,90 & 68,46 \\
VAM (\%): & $>15$ & 17,01 & 16,09 & 15,26 & 13,04 \\
M. esp. Máx. Medida (ton/m ( $^{3}$ ): & -- & 2,398 & 2,393 & 2,407 & 2,432 \\
M. esp. aparente (ton $/ \mathrm{m}^{3}$ ): & -- & 2,302 & 2,299 & 2,308 & 2,329 \\
RelaçãoFiller/Betume add: & 0,6 a 1,6 (SUPERPAVE) & 1,00 & 1,06 & 1,07 & 1,22 \\
\hline
\end{tabular}

Para a produção das misturas asfálticas recicladas, uma usina do tipo volumétrica - de tambor 
secador e misturador externo - foi adaptada para recebimento de até $30 \%$ de RAP nas misturas convencionais, com silo próprio para o material fresado e correia transportadora para entrada deste diretamente no misturador do equipamento. O posicionamento do silo de entrada do RAP na usina em relação ao posicionamento da mesma está ilustrado no croqui da Figura 3.

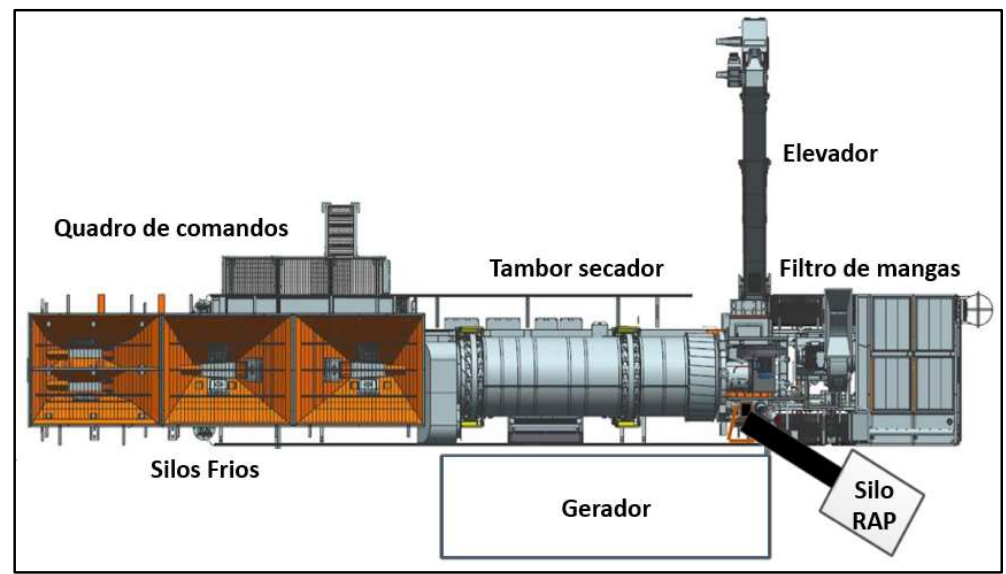

Figura 3: Croqui da implantação de silo para entrada de RAP.

O RAP passou por um processo de separação das frações graúdas (retidas na peneira 3/4") das miúdas. Entretanto, em um primeiro teste realizado apenas com uma "grelha vertical" de tamanho 3/4", as misturas não tiveram um bom comportamento quanto a sua homogeneização e envolvimento de ligante nos agregados. O peneiramento com malha $3 / 4$ " garantiu o andamento correto no processo de misturas. Ilustrase o processo na Figura 4.

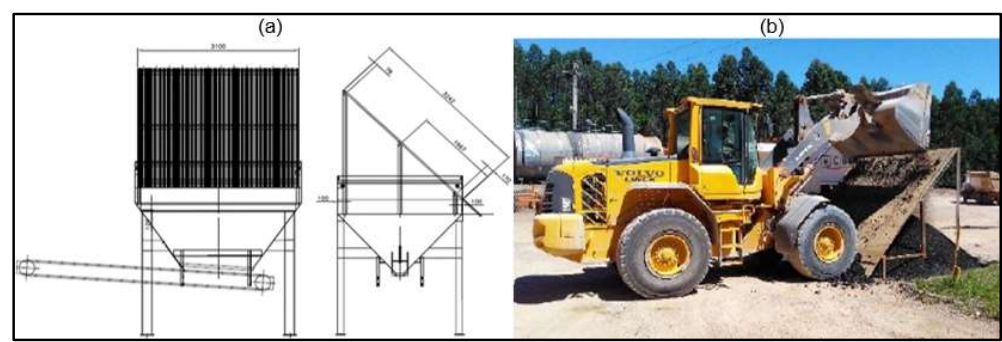

Figura 4: Estrutura para beneficiamento RAP (a) e teste realizado (b)

O processo de usinagem evoluiu da maneira tradicional sem a inserção de fresado interferir na produção. Outro detalhe importante no momento da operação da usina foi o sobreaquecimento dos agregados virgens de forma a aquecer por contato o RAP. Nos dias que antecederam a usinagem, o RAP passou por processo de "tombamentos", o qual serviu para redução da umidade presente no material. Baseando-se nas recomendações da NAPA, o conhecimento do teor de umidade para o agregado de 1,25\% e RAP de 2,83\% e particularidades da usina, as temperaturas de aquecimento dos agregados adotadas para cada uma das misturas propostas estão descritas na Tabela 4.

Tabela 4: Temperatura de aquecimento de agregados e final desejada da mistura

\begin{tabular}{lll}
\hline Mistura & Temp. Aquecimento agregados $\left({ }^{\circ} \mathrm{C}\right)$ & Temp. final de mistura $\left({ }^{\circ} \mathrm{C}\right)$ \\
\hline M0 & 180 & 165 \\
M10 & 201 & 165 \\
M20 & 233 & 165 \\
M30 & 252 & 165 \\
\hline
\end{tabular}


Seguindo a norma DNER PRO 013/94, aproximadamente, 1350 quilos de amostras foram coletados e encaminhados para o Grupo de Estudos e Pesquisas em Pavimentação e Segurança Viária (GEPPASV) no Laboratório de Materiais de Construção Civil (LMCC) da Universidade Federal de Santa Maria (UFSM). No laboratório, as misturas foram levadas à estufa para aquecimento, por duas horas a aproximadamente $110^{\circ} \mathrm{C}$, até a estabilização para posterior inserção das amostras no misturador na temperatura de compactação.

As amostras foram colocadas em um misturador planetário (Infratest modelo Bituminous Laboratory Mixer) na temperatura adotada para a compactação dos corpos de prova foi de $142^{\circ} \mathrm{C}$, intervalo médio proposto no laudo do distribuidor de CAP. Ainda, em função dos diferentes tamanhos nos diversos ensaios, a moldagem dos corpos de prova seguiu as especificações da norma NBR 15987 - Misturas asfálticas à quente - Preparação de corpos de prova com compactador giratório - IPC SERVOPAC Giratory Compactor. No processo de compactação, foi aplicada pressão de $0,60 \mathrm{MPa}$, utilização de ângulo de rotação externo de 1,25 e velocidade constante de $30 \mathrm{rpm}$. Foram moldados 48 corpos de prova de altura de 6,4 e $52 \mathrm{com} 16 \mathrm{~cm}$ de altura, todos com diâmetro médio de $10 \mathrm{~cm}$. Para a obtenção do volume de vazios correto, a massa das amostras foi calculada em função da massa específica máxima medida $(\mathrm{Gmm})$ e a altura fixada em 16 ou $6,4 \mathrm{~cm}$, conforme o caso.

Para os ensaios de avaliação mecânica das misturas foram realizados ensaios de deformabilidade (Módulo de Resiliência pelo DNIT 135/2018 e Módulo Complexo através da AASHTO T 342-11), danificação (Flow Number, Resistência a Tração e Fadiga a Tração Compressão utilizando as normas AASHTO TP 79-15, DNIT 135/2018 e AASHTO TP 107-14, respectivamente) e adesão/coesão (Desgaste por abrasão, DNER - ME 383/99 e Dano por Umidade Induzida, DNIT 180/2018) das misturas. Mais detalhes dos procedimentos podem ser encontrados em Luzzi (2019)].

\section{RESULTADOS E DISCUSSÃO}

\section{Procedimentos de Campo}

Foram realizadas etapas de controle no material fresado antes de sua inserção na usina e elaboração dos projetos. Em um primeiro teste realizado, o material fresado foi peneirado em uma "grelha vertical" de diâmetro 3/4" com o intuito de enquadrar todas as granulometrias dentro da faixa " $C$ " das diretrizes da DNIT ES 031/2006. Na Figura 5 está ilustrado o método utilizado para a separação das frações do RAP em agregado graúdo (retido na 3/4" e não utilizado) e miúdo (passante na grelha 3/4").

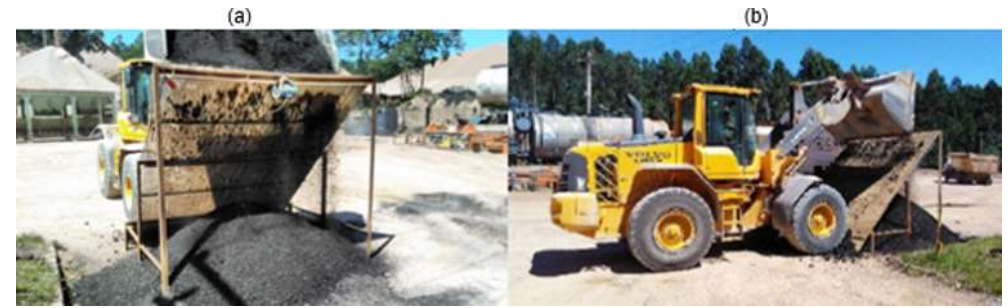

Figura 5: Processo de separação das frações do RAP: vista inferior (a) do peneiramento e posicionamento da carregadeira (b).

O material passante na grelha ainda possuía alguns grumos, mas o teste de usinagem prosseguiu em 
virtude da possibilidade de a usina processar, com eficiência, as misturas. Na M10, o procedimento de mistura ocorreu de maneira normal sem prejuízos no âmbito da homogeneização da mistura e envolvimento dos agregados. No processamento da M20, grumos começaram a aparecer no produto final, identificando uma certa ineficiência do misturador ao processar tamanha quantidade de RAP em tamanho inapropriado à curva granulométrica. Quando da usinagem da M30, verificou-se, além da já citada anteriormente, outra inadequação na mistura produzida. O ligante asfáltico virgem adicionado não envolveu a mistura de agregados e RAP por completo, notando-se assim a necessidade de melhoramento no beneficiamento do material fresado ou até mesmo no processo de usinagem. Na Figura 6 estão estes pontos de inadequação das misturas.

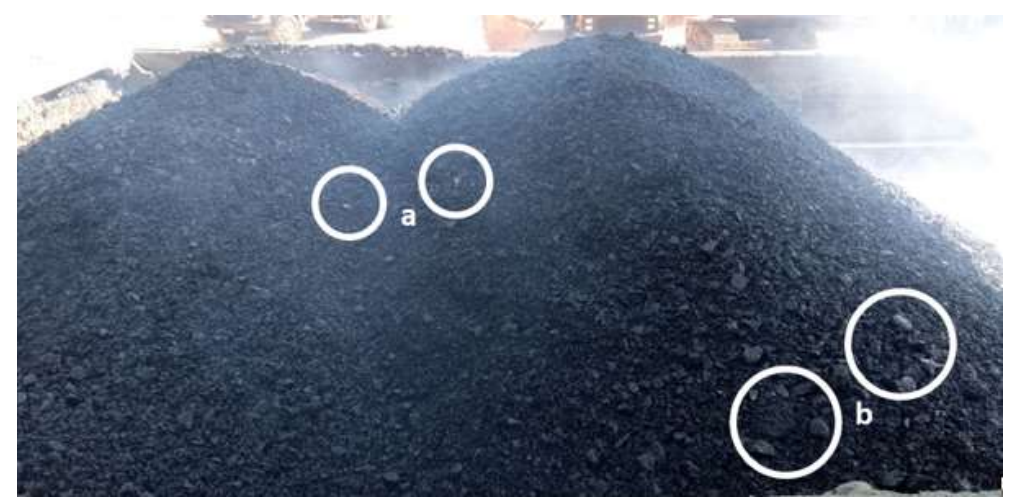

Figura 6: Falta de envolvimento de ligante (a) e grumos nas misturas produzidas (b).

No peneiramento na malha 3/4", em torno de 70 a $80 \%$ do RAP pôde ser aproveitado e, para percentuais maiores, a britagem se torna necessária. Para a usinagem final, foram peneiradas 150 toneladas de RAP e este foi estocado em base impermeável, construída também em concreto asfáltico, e protegido com lonas contra intempéries e contaminação.

Para os testes e usinagem final das misturas, foram realizadas as implementações do silo e correia transportadora para o RAP. Os pés do silo foram adaptados para a correta altura na saída da correia transportadora e com auxílio de uma escavadeira hidráulica, o silo foi posicionado de maneira não perpendicular à usina (Figura 7).

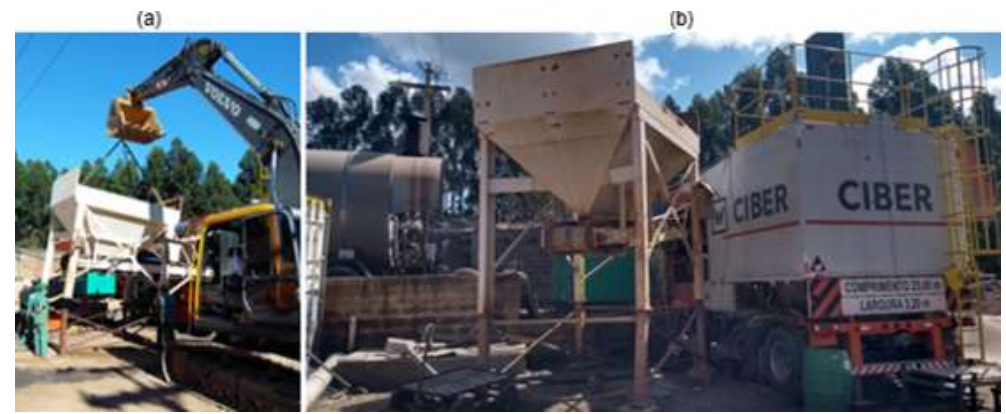

Figura 7: Instalação (a) e posicionamento do silo alimentador de RAP em relação a usina (b).

Devido ao posicionamento do silo dosador de RAP, um ajuste na entrada do misturador precisou ser realizado (Figura 8): direcionamento do RAP através de calha metálica ao final da correia transportadora. Esta estrutura permitiu a vazão de material fresado dentro do misturador da usina de maneira suave, garantindo um fluxo contínuo de incorporação de RAP e evitando perdas de material pela altura de queda. 


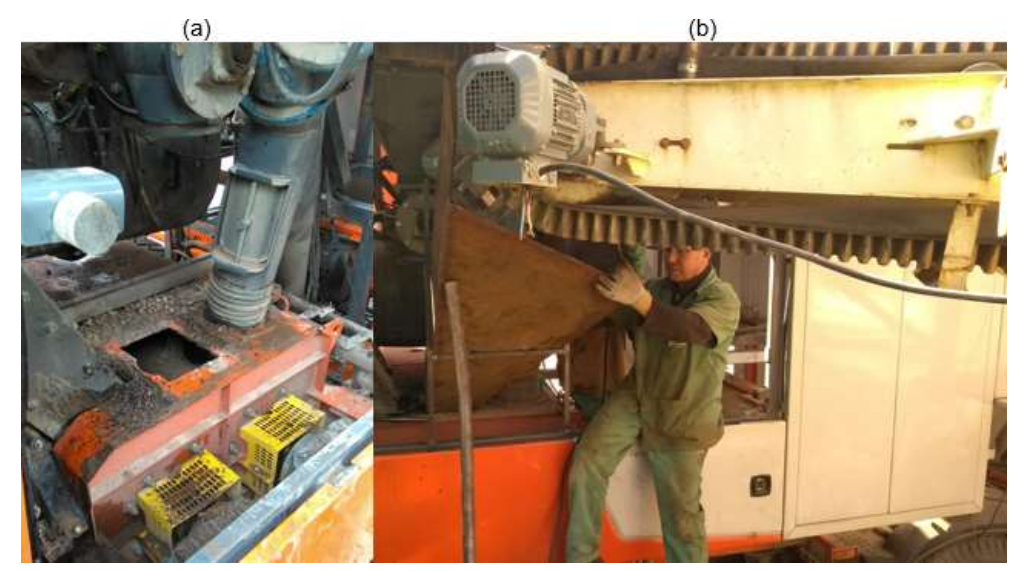

Figura 8: Entrada do RAP: abertura superior (a) e calha instalada no final da correia (b).

No momento da usinagem, a alimentação do silo de RAP foi realizada com uma escavadeira hidráulica. Cabe ressaltar que a entrada de RAP na usina não foi totalmente automatizada e a vazão deste foi calculada através da velocidade da correia transportadora e a abertura dosadora na saída inferior do silo. 0 restante do procedimento de usinagem foi realizado de maneira tradicional, procurando se manter os limites de sobreaquecimento dos agregados e temperatura final de misturas, as faixas especificadas e inserção de teores de projeto de ligante asfáltico. Foram produzidas 330 toneladas de cada uma das 4 massas estudadas, as quais foram aplicadas em campo de forma convencional. Após coletadas misturas, para a avaliação do controle tecnológico, foram levadas a laboratório para a determinação do teor de ligante com o intuito de facilitar o entendimento e comportamento dos resultados obtidos nos ensaios mecânicos, bem como a avaliação da performance da implementação do silo dosador e correia transportadora de RAP. Na Tabela 5 estão dispostos os valores médios de 9 amostras para cada mistura.

Tabela 5: Teor de ligante obtido depois do processo de usinagem.

\begin{tabular}{llllll}
\hline Projeto & Teor de ligante novo inserido & \% ligante final esperado & \% ligante após usinagem & Erro Absoluto & Diferença \\
\hline M0 & $5,65 \%$ & $5,65 \%$ & $5,01 \%$ & $0,64 \%$ & $-11,33 \%$ \\
M10 & $5,30 \%$ & $5,58 \%$ & $4,89 \%$ & $0,69 \%$ & $-12,37 \%$ \\
M20 & $4,85 \%$ & $5,51 \%$ & $4,87 \%$ & $0,88 \%$ & $-11,62 \%$ \\
M30 & $3,87 \%$ & $5,44 \%$ & $5,39 \%$ & $0,05 \%$ & $-0,92 \%$ \\
\hline
\end{tabular}

Verifica-se na Tabela 5 que, excetuando-se a M30, os teores não se enquadraram no ótimo de projeto esperado. A calibração da própria usina volumétrica, a inserção inadequada de ligante asfáltico e a não total eficiência do processo de mistura podem ser causas deste comportamento. O comportamento da M30 pode estar atribuído ao processo contínuo de produção da usinagem. As curvas granulométricas das amostras também foram avaliadas, as quais estão ilustradas na Figura 9, o projetado incialmente e após a usinagem. Verifica-se que, para todas as misturas, o comportamento das curvas se manteve e tornou-se um pouco mais fina entre as peneiras de $n^{\circ} 10$ a 3/4", para as misturas com adição de RAP. 

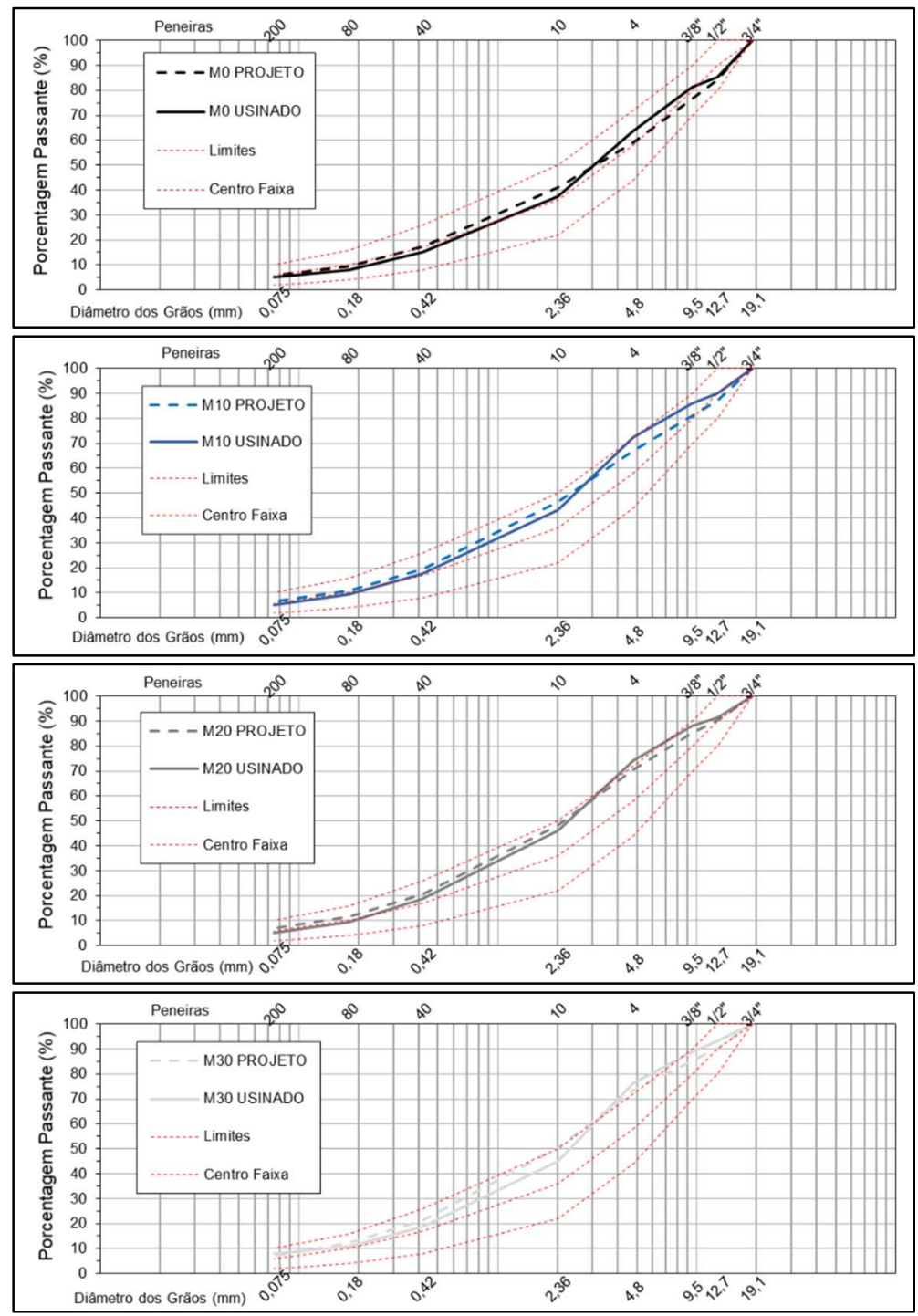

Figura 9: Curvas granulométricas: projetado e após a usinagem.

\section{Ensaios Laboratoriais}

\section{Módulo de Resiliência}

Os dados de MR foram extraídos do software UTS003 (Indirect Tensile Módulus Test) através da UTM - 25 e estão expostos na Figura 10, comparando-os aos de outras pesquisas.

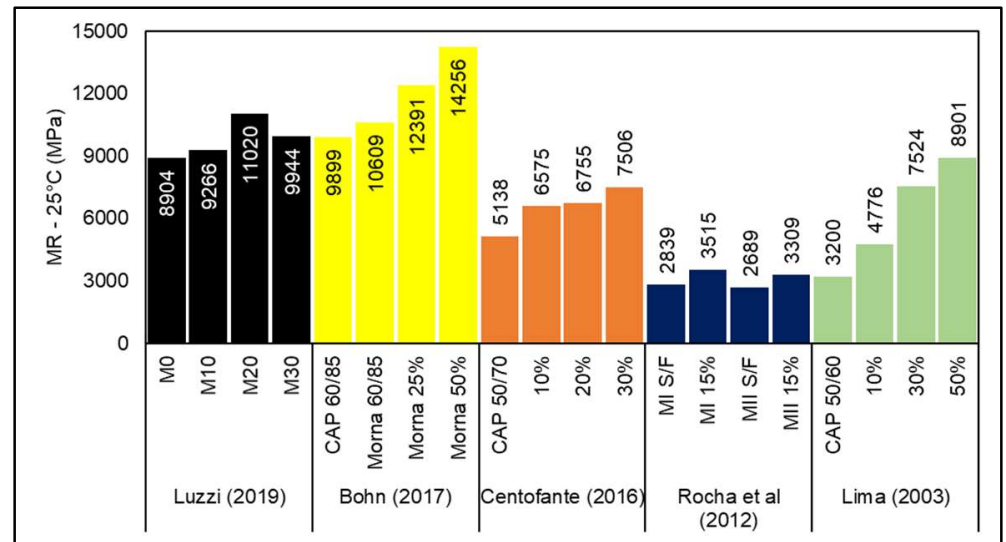

Figura 10: Comparação dos dados de Módulo de Resiliência com os dados desta pesquisa, Bohn (2020), Centofante (2018), Rocha et al. (2012) e Lima (2003). 
Verifica-se que o valor de módulo de resiliência sofre um acréscimo conforme aumenta-se o teor de material fresado incorporado à mistura, excetuando-se a relação entre a M20 e M30, onde nota-se um pequeno decréscimo no valor médio do parâmetro. Esta pequena queda no valor no Módulo de Resiliência pode estar associada ao maior teor de ligante total final encontrado na mistura com 30\% de fresado, a tornando menos rígida quando em comparação a M10 e M20. Em função do comportamento, avalia-se, de acordo com o esperado, que há um aumento de rigidez com o incremento de RAP as misturas asfálticas convencionais.

\section{Módulo Complexo}

Os dados de Módulo Dinâmico (|E*|) e Ângulo de Fase ( $\phi)$ foram obtidos através da AASHTO T 342 11. O software utilizado (UTSO06 - SPT Dynamic Modulus Test) que admite 10 frequências de ensaios - 25, $20,10,5,2,1,0,5,0,2,0,1$ e $0,01 \mathrm{~Hz}$ - e as temperaturas utilizadas foram $-10,4,21,37$ e $54^{\circ} \mathrm{C}$ para duas amostras de cada uma das misturas. Na Figura 11 estão dispostas as representações no espaço Cole-Cole, Diagrama Black e Curvas Mestras de Módulo Dinâmico e Ângulo de Fase para todas as misturas, elaboradas a partir da modelagem 2S2P1D.
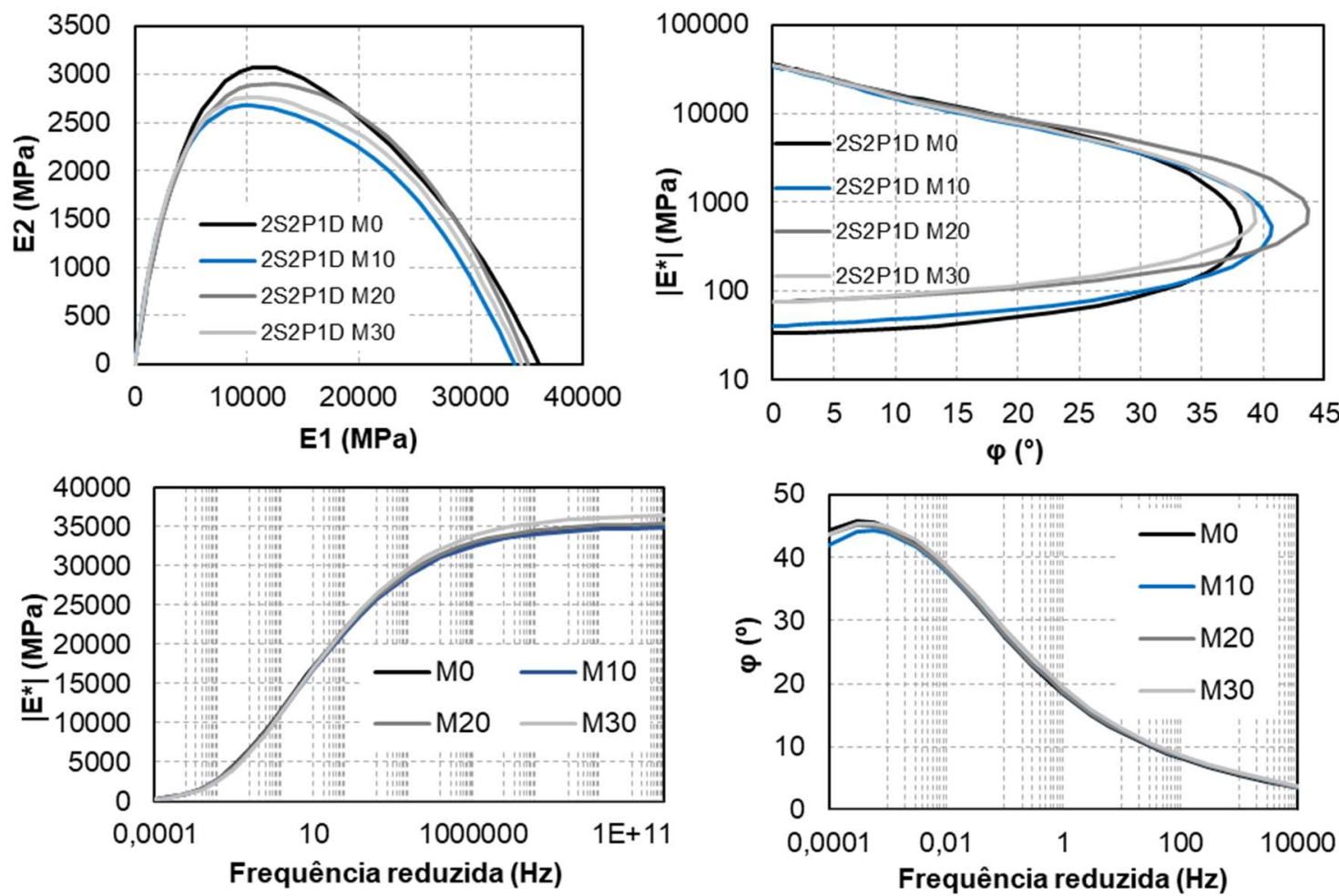

Figura 11: Cole-Cole, Diagrama Black e Curvas Mestras das misturas.

Não se observa um comportamento definido em função dos percentuais de RAP inseridos, visto que as curvas apresentadas possuem valores muito próximos e não se pode definir uma maior representatividade viscosa ou elástica das misturas, não inferindo melhor comportamento ao desempenho à fadiga ou a deformação permanente das misturas.

Os dados apresentados estão coerentes com os dados apresentados pela norma da AASHTO M 323 - 13 - Superpave Volumetric Mix Design, na qual é descrito que misturas asfálticas com até 15\% de fresado 
não precisam de nenhuma seleção ou modificação de ligante asfáltico, no intervalo de inserção de RAP entre 15 e $25 \%$, um ligante com um grau de performance inferior ao da mistura de referência deve ser utilizado e acima de $25 \%$, características específicas finais desejadas para as misturas devem ser levadas em consideração. Deste modo, avalia-se que o comportamento não determinado dos parâmetros em função da inserção de material fresado é esperado e aceitável.

\section{Desgaste Cântabro}

No ensaio para a verificação da resistência ao desgaste por perda de massa, 3 corpos de prova com volume de vazios em $4 \pm 1 \%$ foram condicionados por 12 horas a $25^{\circ} \mathrm{C}$ e submetidos a 300 revoluções no tambor da máquina Los Angeles, de acordo com a norma DNER - ME 383/99.

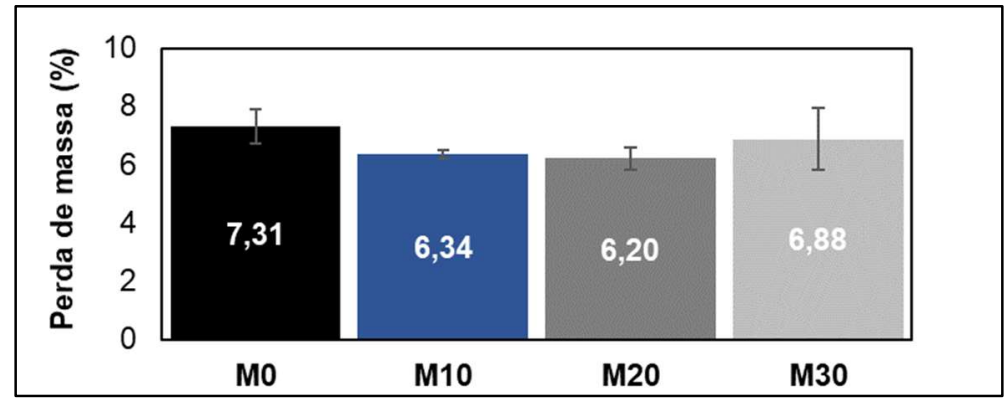

Figura 12: Resultados de abrasão pelo desgaste Cântabro.

Verifica-se que, a partir dos dados expostos na Figura 12, para as 4 misturas avaliadas o desgaste por abrasão ficou bem abaixo do especificado (25\%), não perdendo mais que 8,0\% em massa. Nota-se que não há um comportamento visível à perda de massa em função da inserção de RAP.

\section{Dano por Umidade Induzida}

O ensaio de Dano por Umidade Induzida (DUI - Lotmann Modificado) foi realizado para avaliar o efeito deletério da água na propriedade de adesividade das misturas. Foram moldadas 6 amostras de cada uma das misturas, sendo que em um grupo de 3 amostras foi realizada apenas o ensaio de resistência a tração por compressão diametral e um segundo grupo de 3 amostras passou por condicionamento, conforme DNIT 180/2018 ME. Os resultados obtidos de resistência a tração antes e depois do condicionamento estão ilustradas no gráfico da Figura 13.

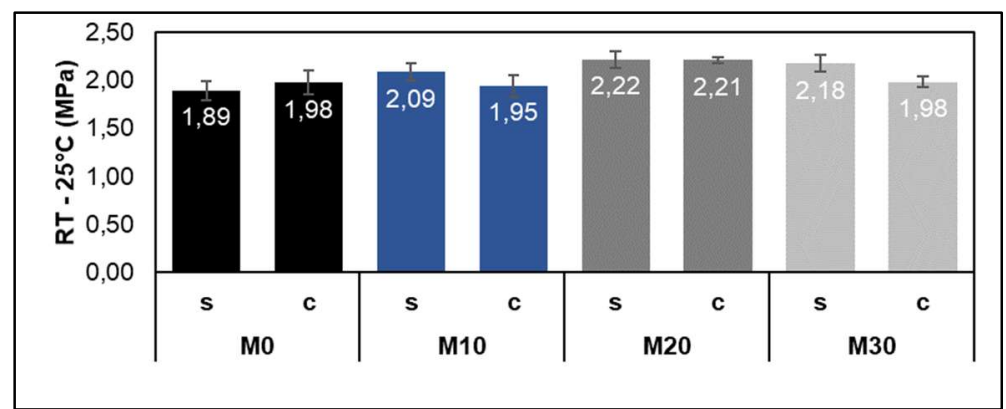

Figura 13: Resultados de Lotmann Modificado para todas as misturas.

Verifica-se, ainda, que para a mistura de referência, a RT melhorou seu desempenho após o 
condicionamento da amostra. Isto evidencia a influência não negativa do efeito da água nas misturas. De acordo com a ES 031/2006 do DNIT, a razão da resistência à tração (RRT) por compressão diametral estática antes e após o condicionamento deve ser superior a 0,7 , ou seja, $70 \%$ da RT encontrada incialmente nas misturas, sem condicionamento. De acordo com a metodologia SUPERPAVE, os resultados obtidos nesta relação vem estar acima de 0,8.

Os resultados encontrados de DUI foram 104,36, 93,13, 99,85 e 91,04\%, respectivamente, para M0, M10, M20 e M30. Nota-se que todas as misturas desta pesquisa se enquadraram dentro do especificado e, também o que preconiza o método SUPERPAVE de dimensionamento.

\section{Flow Number}

Este ensaio relaciona-se com a capacidade de a mistura resistir a deformações permanentes, onde verifica-se que quanto maior o número de ciclos e menor a deformação acumulada, menor é a propensão do pavimento à formação de trilhas de roda. Para cada uma das misturas foram ensaiados 3 corpos de prova a $60^{\circ} \mathrm{C}$ conforme norma AASHTO TP 79-15. Com os dados levantados por amostra, pôde-se determinar os valores médios de ciclos e, como ilustrado na Figura 14, compará-los a outras pesquisas.

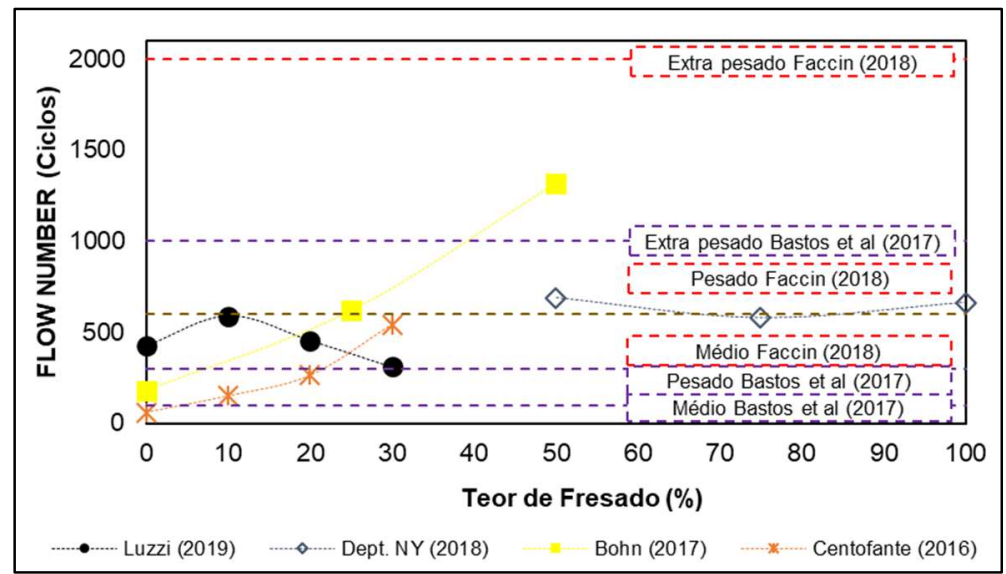

Figura 14: Comparação de resultados de Flow Number entre outros trabalhos e esta pesquisa.

Nota-se que a influência da incorporação de RAP nas misturas tem um comportamento determinado, sendo a M10 que tem os maiores resultados de Flow Number, com 590 ciclos. Verifica-se que quanto maior o percentual de RAP adicionado, pior é o comportamento a deformação permanente das misturas.

Ressalta-se que a influência do teor de ligante final encontrado nas misturas se sobressai ao percentual de RAP inserido, visto que o teor de ligante da mistura com menor número de ciclos (M30) é meio ponto percentual maior aos das outras misturas. Mesmo com a redução avaliada, é importante ressaltar que todas as misturas estudadas, de acordo com os limites propostos por Nascimento (2008), podem ser utilizadas em rodovias de tráfego médio.

\section{Resistência à Tração por Compressão Diametral}

Foram utilizados $3 \mathrm{CP}$ 's por projeto, sendo estes acondicionados na temperatura de ensaios de $25^{\circ} \mathrm{C}$ por 12 horas. No gráfico da Figura 15, verifica-se que há proporcionalidade no aumento da RT obtida com o 
percentual de RAP utilizado na mistura. Nota-se, apenas, uma queda entre os projetos M20 e M30.

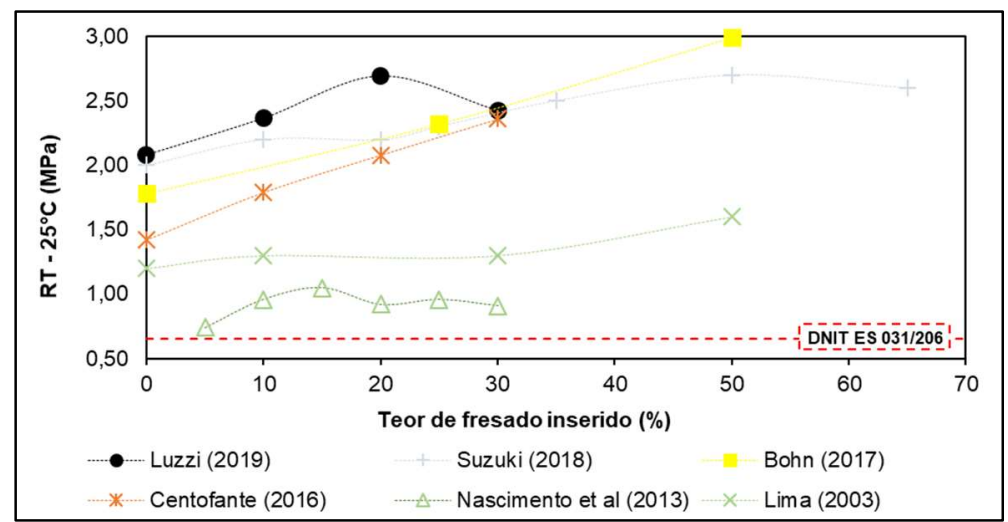

Figura 15: Valores de Resistência a Tração desta pesquisa e em comparação a outras.

Nas especificações brasileiras, a DNIT ES 031/2006 exige mínimo de 0,65 MPa para misturas asfálticas com ligante convencional, enquanto a DNER 385/99 determina que misturas asfálticas com ligante modificado por polímero devem possuir valores entre 0,7 e 1,2 MPa. Avalia-se como satisfatório os resultados encontrados nesta pesquisa.

\section{Fadiga à Tração-Compressão}

A análise à fadiga foi realizada com dados provenientes do modelo S-VECD, como as curvas características de dano (Cvs S) e as envoltórias de ruptura do critério de falha GR. Estes dados foram inseridos no software LVECD (Layered Viscoelastic Pavement Analysis For Critical Distresses) e pôde-se avaliar as curvas de dano médio acumulado e também o dano por fadiga quando aplicados a estruturas típicas de pavimentos (NASCIMENTO, 2015; BOEIRA, 2018; SCHUSTER, 2018)

O modelo S-VECD foi ajustado para diferentes magnitudes de deformação, sendo que em cada amostra um nível pré-determinado foi estabelecido, variando de 200 a 300 microstrain. Anteriormente a cada ensaio, realizou-se um teste de 'fingerprint', ou seja, um ensaio de módulo dinâmico de traçãocompressão de curto prazo para obter a variação da rigidez entre as amostras. Com os dados do ensaio de módulo complexo e de fadiga tração-compressão, se elabora a curva C (integridade do material) vs $\mathrm{S}$ (acúmulo de dano), a qual representa uma característica do material. Na Figura 16 estão as curvas C vs S para todas as misturas estudadas.

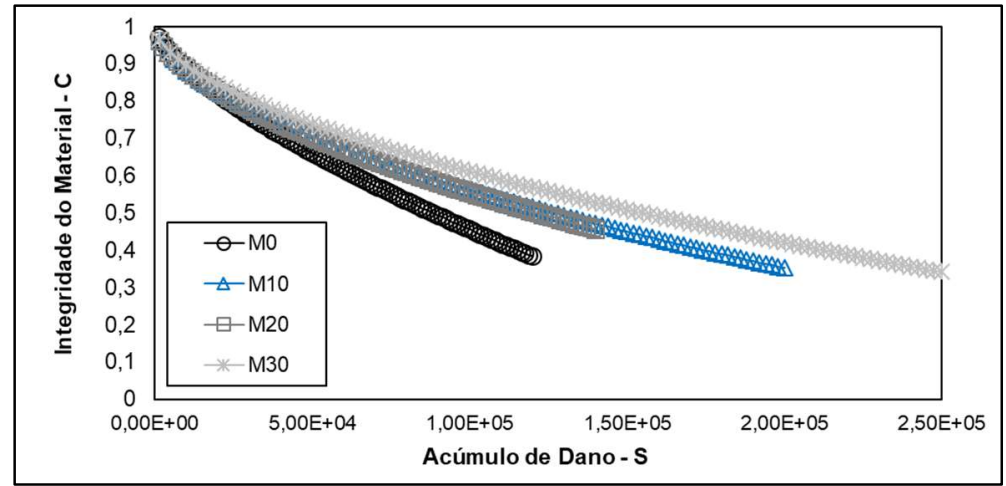

Figura 16: Curvas $C$ vs $S$ para todas as misturas. 
Com o comportamento da integridade e evolução do dano é possível inferir o desempenho à fadiga das misturas, mas avalia-se melhor com as envoltórias de ruptura e com as simulações em estruturas típicas de pavimentos. O critério de fadiga adotado foi o desenvolvido por Sabouri et al. (2014), onde a taxa de variação média de energia de pseudo deformação liberada por ciclo de ensaio (GR), gerando as envoltórias de ruptura GR vs Nf. Pelo modelo de potência, apresentado pela equação $\boldsymbol{G}^{\boldsymbol{R}}=\boldsymbol{Y} \boldsymbol{x} \boldsymbol{N}_{\boldsymbol{f}}^{\Delta}$, as envoltórias são ajustadas e apresentam formato linear na escala logarítmica. O Y e o $\Delta$ são os coeficientes do critério de ruptura Gr versus Nf. Assim, as envoltórias de ruptura GR vs Nf também foram geradas (Figura 17), e bem como as curvas C vs S, são únicas para cada material. Segundo Sabouri et al. (2014), isto a torna uma propriedade fundamental do material na resistência ao dano, sendo ainda, independente da temperatura e do modo de carregamento. As misturas que tendem a um melhor desempenho à fadiga apresentam envoltórias mais acima e a direita no gráfico, além de menores inclinações.

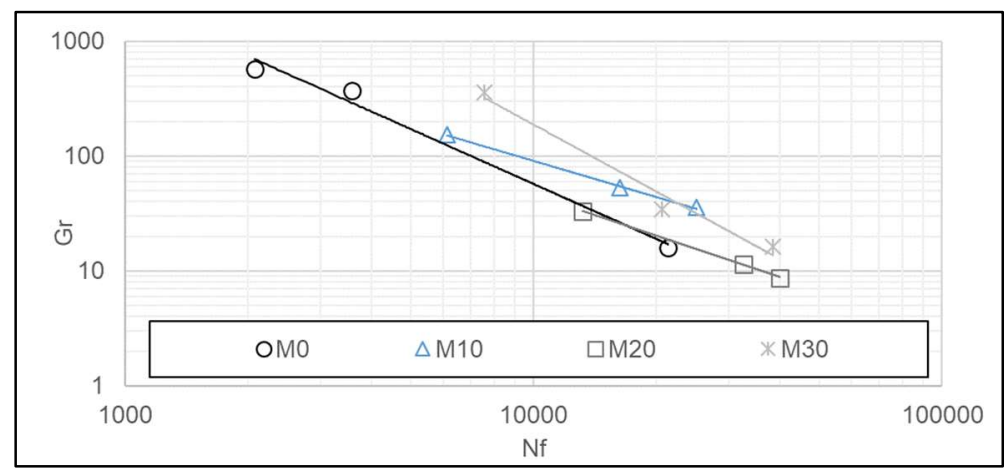

Figura 17: Envoltórias de ruptura GR vs Nf para todas as misturas.

Uma segunda análise realizada foi a utilização da simulação de ciclos de ruptura desenvolvida por Nascimento (2015), onde abrange-se os parâmetros das curvas C vs S, as envoltórias de ruptura GR e os dados da caracterização viscoelástica. Este método é considerado o mais próximo da realidade do ensaio. Os resultados estão plotados no gráfico da Figura 18.

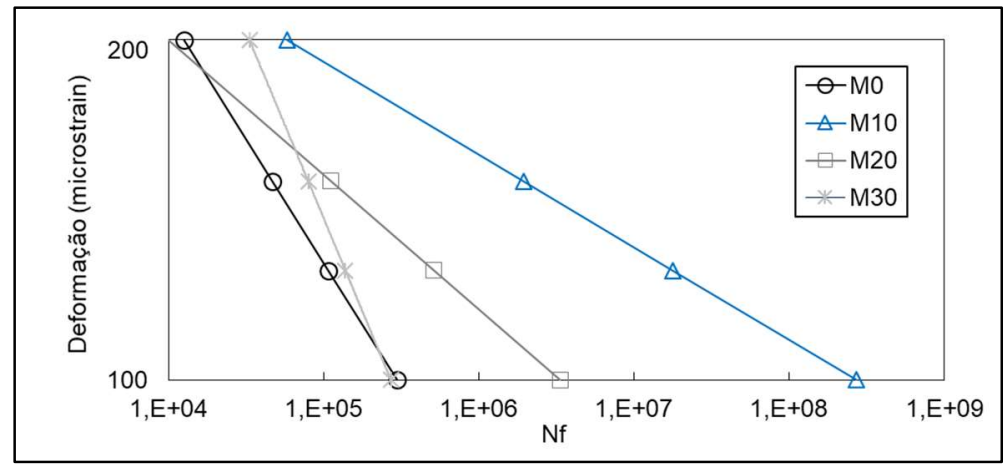

Figura 18: Simulação de $\mathrm{Nf}$ a partir $\mathrm{GR}, 19^{\circ} \mathrm{C}$ e $10 \mathrm{~Hz}$

A partir das envoltórias de GR e da simulação de Nf, verifica-se que M10 e M20 tenham um possível desempenho melhor à fadiga, bem como M0, possivelmente, o pior.

Para o cálculo do dano (N/Nf) no LVECD, foram elaboradas estruturas seguindo o padrão da Figura 19, alterando a espessura do revestimento de 5, 10 e 15cm, avaliando-se separadamente a influência das camadas no desempenho à fadiga. Ainda, utilizou-se o clima de Curitiba/PR (por já ter banco de dados no 
software), camadas não aderidas entre si, carga de eixo padrão (8200 Kgf), distância entre rodas de 0,325m e pressão dos pneus de 0,56 MPa distribuídos sobre uma área circular.

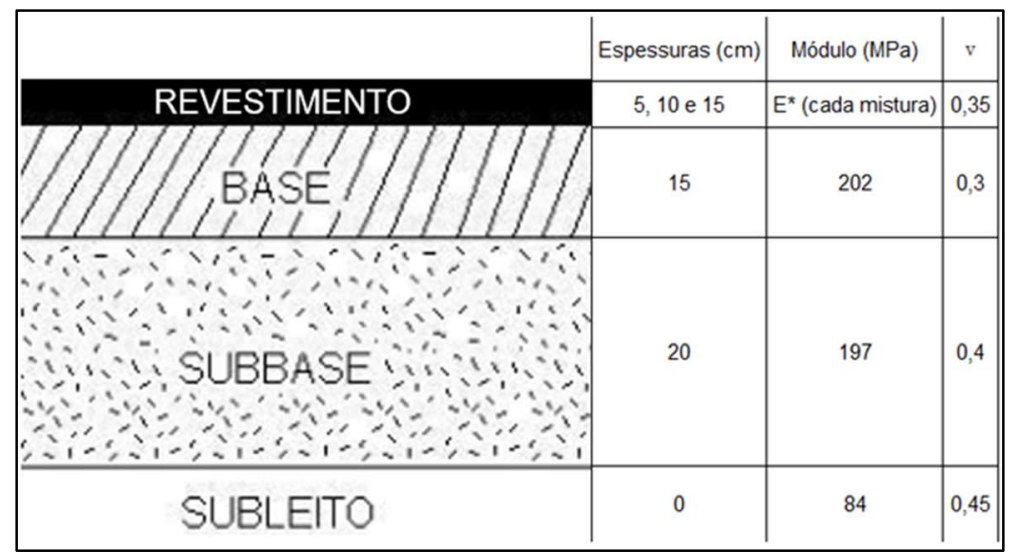

Figura 19: Estruturas utilizadas para análise dos dados no LVECD.

As três estruturas foram simuladas a um tráfego, para 120 meses - tempo final de projeto -, de $\mathbf{5 x 1 0}^{6}, 1 \times 10^{7}$ e $\mathbf{5 x 1 0}^{7}$. No LVECD, os valores de pseudo rigidez e a relação de dano (N/Nf) são calculadas em pontos diferentes na espessura da camada asfáltica. A N/Nf é encontrada a partir do critério de falha GR e os valores variam de 0 (sem danos) a 1 (totalmente danificada). Na Figura 20 estão as curvas de dano acumulado encontrados para todas as misturas.
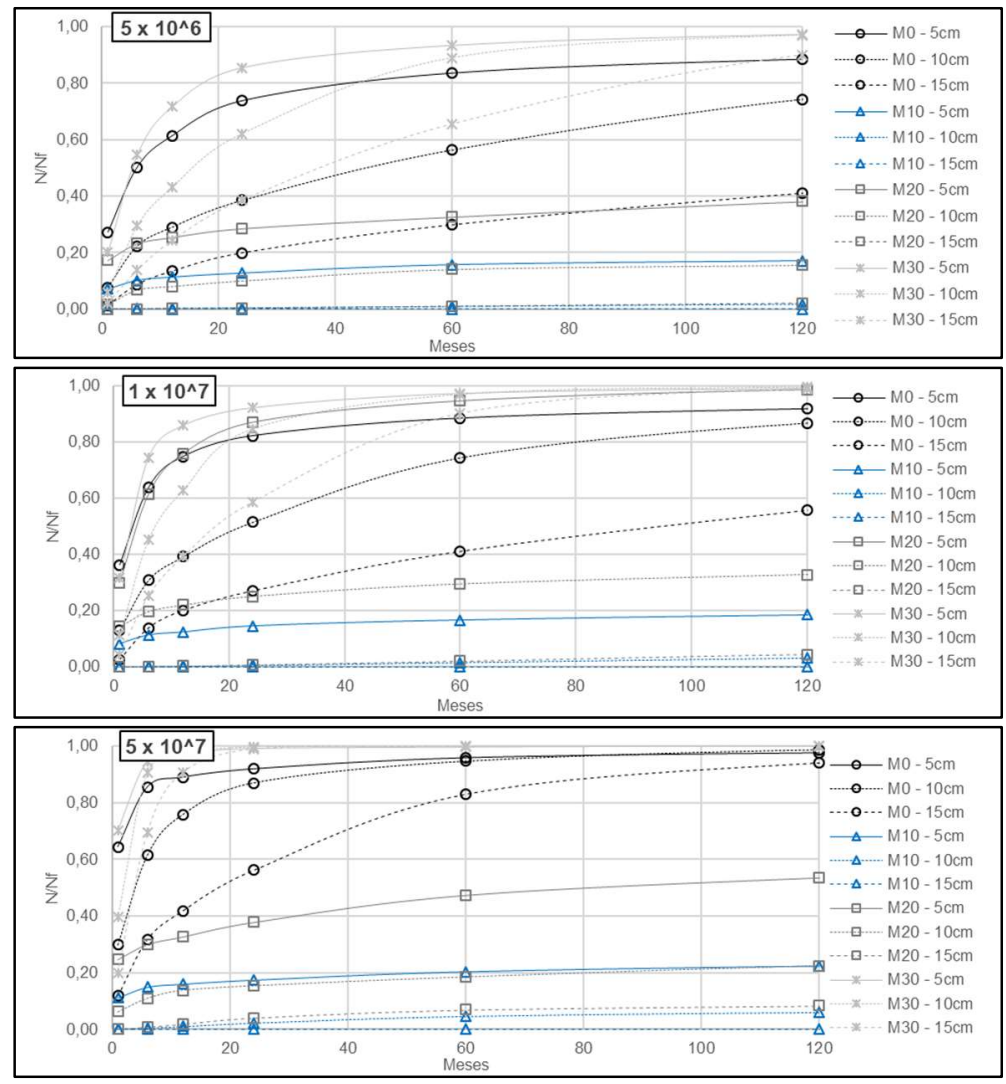

Figura 20: Dano acumulado de 120 meses para todas as misturas.

Verifica-se que o dano acumulado diminui com o aumento da espessura do revestimento, bem como sofre um decréscimo com o aumento do tráfego, como era de se esperar. É importante salientar que, mesmo nas situações mais críticas, os valores de dano estão próximos a 0,60 para M20 e 0,20 para M10. Ainda, nota- 
se que valores de dano são praticamente nulos quando se avalia M10 e M20 com revestimentos mais espessos e menores volumes de tráfego. Nas misturas $\mathrm{M0}$ e $\mathrm{M} 30$, o resultado encontrado correspondeu às simulações de Nf e das envoltórias de ruptura GR, sendo as duas de pior comportamento em relação ao dano acumulado em virtude de fadiga.

Para facilitar o entendimento do comportamento do dano acumulado, transformou-se, através da função de transferência de Nascimento (2015), dano acumulado em percentual de área trincada de revestimento. Esta função de transferência tem uma abordagem da viscoelasticidade e em ensaios mecânicos utilizando dados de campo e laboratório estudados e monitorado pela Rede Temática de Asfalto em diversos estados brasileiros.

Adotou-se $20 \%$ de limitante para avaliação das misturas, pois este valor condiz com a realidade de um pavimento severamente trincado (PINTO 1991; DNIT, 2006). A Figura 21 demonstra todas as curvas de percentual de área trincada nos VDM estudados para todas as misturas.
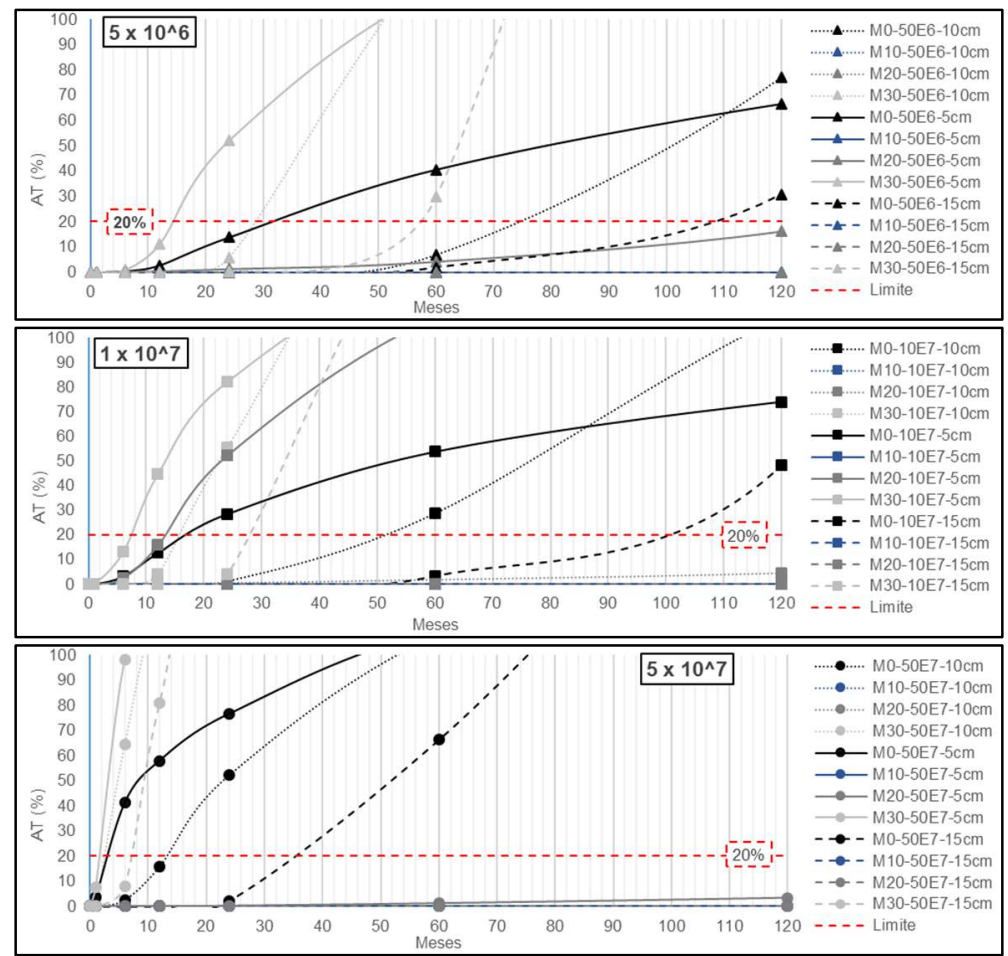

Figura 21: Percentual de área trincada de todas as misturas.

Na Figura 21 pode-se notar que as misturas M10 e M20, praticamente, não possuem percentuais de área trincada, corroborando ao avaliado anteriormente, tanto para as envoltórias de GR quanto para a simulação de Nf pela equação de Nascimento (2015). Estas duas misturas demonstram um padrão acima das outras duas no desempenho à fadiga, demonstrando a viabilidade de aplicação destas para qualquer fluxo de tráfego, não extrapolando os simulados. Novamente, nota-se, para M0 e M30, um pior desempenho frente à fadiga. Pode-se destacar a maior relevância relacionada a espessura do revestimento, já que o aumento deste quesito tem uma influência maior na vida de fadiga da mistura quando comparada ao aumento do VDM. Ainda, comparou-se os comportamentos â fadiga das misturas desta pesquisa com as de Schuster (2018) e Boeira (2018), utilizando-se dos valores do índice Fator de Área de Fadiga (FAF). De acordo 
com Nascimento (2015), este índice se dá por meio do cálculo da área sob a curva de fadiga ( $\varepsilon \times \mathrm{Nf}$ ), em espaço log-log. Simplificadamente, quanto maior o valor do FAF, melhor é o comportamento à fadiga das misturas. Assim, elaborou-se uma classificação de acordo com o FAF (Tabela 6).

Tabela 6: Ranking de misturas pelo FAF calculados pela equação de Nascimento (2008).

\begin{tabular}{lll}
\hline Mistura & FAF & Posição \\
\hline Boeira (2018) AMP M & 2,397 & $1^{\circ}$ \\
Schuster (2018) ECO & 2,394 & $2^{\circ}$ \\
Schuster (2018) AMP & 2,282 & $3^{\circ}$ \\
Schuster (2018) ECO & 2,082 & $4^{\circ}$ \\
Boeira (2018) HIMA M & 2,041 & $5^{\circ}$ \\
Boeira (2018) HIMA S & 2,028 & $6^{\circ}$ \\
M10 & 1,987 & $7^{\circ}$ \\
Boeira (2018) HIMA M & 1,953 & $8^{\circ}$ \\
Boeira (2018) 50/70 M & 1,944 & $9^{\circ}$ \\
Boeira (2018) 50/70 M & 1,800 & $10^{\circ}$ \\
Boeira (2018) AMP M & 1,785 & $11^{\circ}$ \\
Schuster (2018) AMP & 1,750 & $12^{\circ}$ \\
Schuster (2018) AMP & 1,725 & $13^{\circ}$ \\
Boeira (2018) AMP M & 1,709 & $14^{\circ}$ \\
Schuster (2018) AMP & 1,680 & $15^{\circ}$ \\
Boeira (2018) HIMA M & 1,674 & $16^{\circ}$ \\
Schuster (2018) 50/70 & 1,665 & $17^{\circ}$ \\
Schuster (2018) 50/70 & 1,661 & $18^{\circ}$ \\
Boeira (2018) 50/70 M & 1,647 & $19^{\circ}$ \\
Boeira (2018) 50/70 M & 1,638 & $20^{\circ}$ \\
Schuster (2018) 50/70 & 1,628 & $21^{\circ}$ \\
M20 & 1,584 & $22^{\circ}$ \\
Schuster (2018) AMP & 1,567 & $23^{\circ}$ \\
Schuster (2018) AMP & 1,555 & $24^{\circ}$ \\
Schuster (2018) AMP & 1,555 & $25^{\circ}$ \\
Boeira (2018) AMP M & 1,546 & $26^{\circ}$ \\
\hline
\end{tabular}

\begin{tabular}{lll}
\hline Mistura & FAF & Posição \\
\hline Schuster (2018) ECO & 1,542 & $27^{\circ}$ \\
Boeira (2018) HIMA S & 1,512 & $28^{\circ}$ \\
M30 & 1,499 & $29^{\circ}$ \\
Schuster (2018) 50/70 & 1,445 & $30^{\circ}$ \\
M0 & 1,441 & $31^{\circ}$ \\
Schuster (2018) AMP & 1,436 & $32^{\circ}$ \\
Boeira (2018) HIMA S & 1,429 & $33^{\circ}$ \\
Schuster (2018) 50/70 & 1,426 & $34^{\circ}$ \\
Schuster (2018) 50/70 & 1,405 & $35^{\circ}$ \\
Schuster (2018) 50/70 & 1,400 & $36^{\circ}$ \\
Boeira (2018) 50/70 S & 1,383 & $37^{\circ}$ \\
Schuster (2018) 50/70 & 1,382 & $38^{\circ}$ \\
Schuster (2018) 50/70 & 1,376 & $39^{\circ}$ \\
Boeira (2018) HIMA M & 1,374 & $40^{\circ}$ \\
Schuster (2018) 50/70 & 1,368 & $41^{\circ}$ \\
Schuster (2018) 50/70 & 1,351 & $42^{\circ}$ \\
Boeira (2018) HIMA S & 1,331 & $43^{\circ}$ \\
Boeira (2018) AMP S & 1,313 & $44^{\circ}$ \\
Boeira (2018) AMP S & 1,269 & $45^{\circ}$ \\
Boeira (2018) 50/70 S & 1,248 & $46^{\circ}$ \\
Boeira (2018) 50/70 S & 1,178 & $47^{\circ}$ \\
Schuster (2018) AMP & 1,175 & $48^{\circ}$ \\
Boeira (2018) AMP S & 1,175 & $49^{\circ}$ \\
Boeira (2018) AMP S & 1,157 & $50^{\circ}$ \\
Boeira (2018) 50/70 S & 1,156 & $51^{\circ}$ \\
Schuster (2018) TLAF & 1,031 & $52^{\circ}$ \\
\hline
\end{tabular}

Realizou-se, também, utilizando-se de Schuster (2018) e Boeira (2018), a relação entre o FAF e os resultados de Flow Number, expostos na Figura 22.

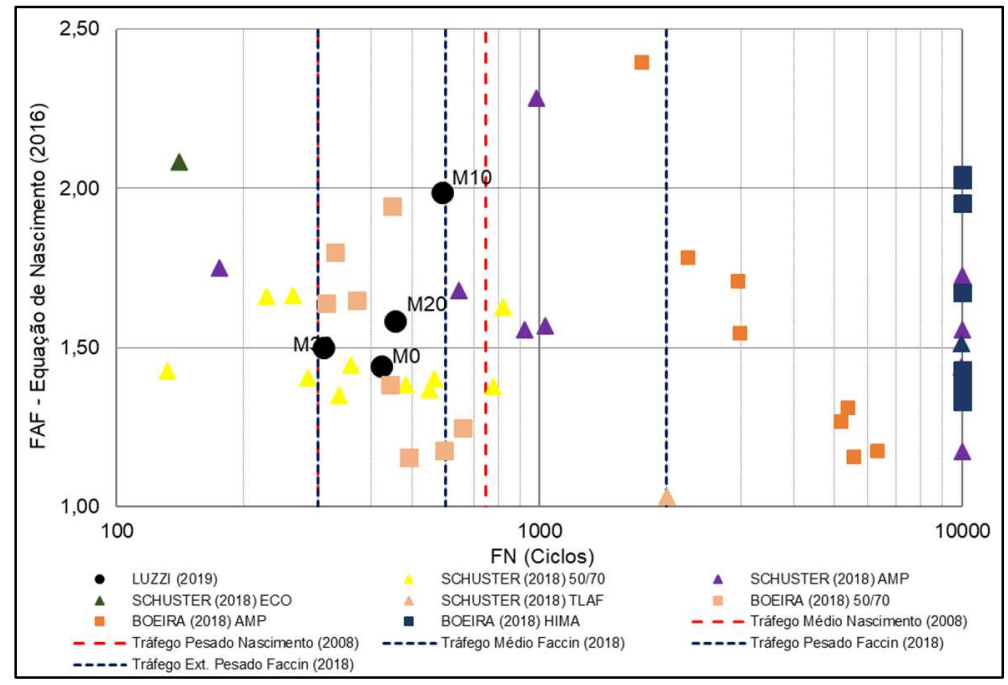

Figura 22: Relação FAF x NF de Luzzi (2019), Schuster (2018) e Boeira (2018).

Vê-se que o comportamento das misturas recicladas é aproximado daquelas com ligante asfáltico 50/70 e em alguns casos se assemelha ou é superior a algumas misturas com ligante modificado por polímero da pesquisa de Schuster (2018). Salienta-se que as misturas desta pesquisa e Schuster (2018) foram produzidas em usinas e por isso podem acarretar em comportamentos diferentes em comparação as de 
Boeira (2018), produzidas em laboratório.

\section{Viabilidade Econômica}

Os materiais asfálticos têm se tornado cada vez mais caros e estes resultados necessitam de uma análise de viabilidade econômica para a motivação da execução de misturas recicladas.

A estrutura exposta na Figura 19 foi deteriorada, sendo os valores de módulo para Base, Sub-base e subleito de 150, 130 e $70 \mathrm{MPa}$, redução de espessura de 15 para 10 na base e 20 para $15 \mathrm{~cm}$ na sub-base, já que a estrutura para M10 e M20 não chegaram a 20\% de área trincada por fadiga em 120 meses e é necessária uma igualdade de condições entre as estruturas.

Para se chegar a um valor de usinagem e aplicação $\left(R \$ / \mathrm{m}^{3}\right)$ foram utilizadas as composições do Sistema de Custos Rodoviários (SICRO)/DNIT de julho/2018 para serviços e preços de materiais asfálticos para o mesmo período - retirados do site da Agência Nacional do Petróleo, Gás Natural e Biocombustíveis (ANP), para o estado do Rio Grande do Sul.

Ainda, no cálculo foram considerados a usinagem, aplicação e transporte de concreto asfáltico, compra e transporte de ligante asfáltico, bem como o transporte do fresado de uma obra de fresagem até o pátio da usina. Cabe aqui salientar que a distância média de transporte tanto para o concreto asfáltico quanto para o do material fresado foi fixada em $60 \mathrm{~km}$. Os custos unitários estão resumidos na Tabela 7.

Tabela 7: Custos de usinagem e aplicação por $\mathrm{m}^{3}$ para cada uma das misturas.

\begin{tabular}{llllll}
\hline Mistura & Ligante + Transp. $\left(\mathrm{R} \$ / \mathrm{m}^{3}\right)$ & Usin. + Apl. CBUQ $\left(\mathrm{R} \$ / \mathrm{m}^{3}\right)$ & Transp. CBUQ $\left(\mathrm{R} \$ / \mathrm{m}^{3}\right)$ & Transp. Fresado $\left(\mathrm{R} \$ / \mathrm{m}^{3}\right)$ & $\mathrm{TOTAL}\left(\mathrm{R} \$ / \mathrm{m}^{3}\right)$ \\
\hline M0 & 347,21 & 266,20 & 63,54 & - & 676,94 \\
M10 & 325,27 & 281,49 & 63,45 & 4,69 & 674,91 \\
M20 & 298,82 & 298,30 & 63,70 & 9,38 & 670,20 \\
M30 & 240,61 & 316,85 & 64,28 & 14,08 & 635,82 \\
\hline
\end{tabular}

Verifica-se que o custo diminui com a inserção de material fresado, visto que o teor de ligante novo inserido reduziu em aproximadamente $28 \%$. Entretanto, a redução não se demonstrou na mesma magnitude $(6,5 \%)$ da diferença encontrada entre os teores ótimos no momento da dosagem dos projetos. Isto pode ter acontecido em razão da adição de novos serviços, bem como um incremento de valor da usinagem das misturas com fresado.

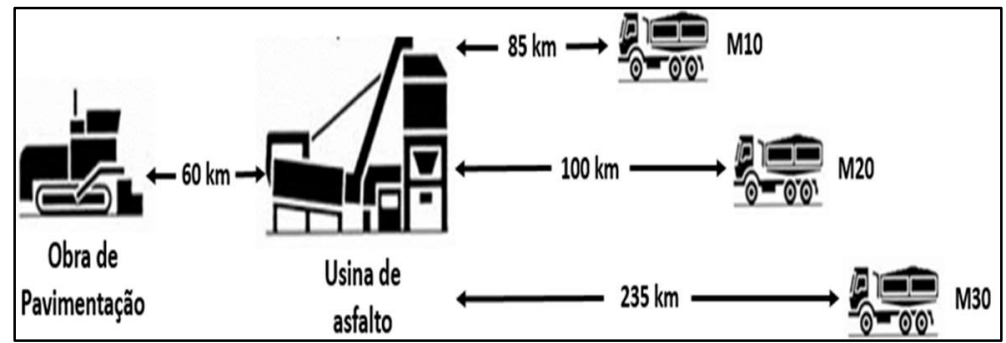

Figura 23: Distâncias de transporte possíveis para o RAP em função do custo das misturas.

Fixando-se a distância de transporte entre a usina e a obra em 60 km, pode-se avaliar as distâncias máximas de transporte de RAP, do estoque/trecho até a usina, as quais, igualariam o preço final das misturas recicladas a $\mathrm{M0}\left(\mathrm{R} \$ 676,94 / \mathrm{m}^{3}\right)$. Nesse critério, a M10 poderia ser utilizada transportando-se fresado de uma 
distância de até $85 \mathrm{~km}$ até usina enquanto a M20 e M30 de 100 e $235 \mathrm{~km}$, respectivamente, conforme ilustrado na Figura 23. Um critério que pode ser mais assertivo foi calculado: o custo da estrutura ao longo da sua vida útil. Mesmo após a deterioração das estruturas, M10 e M20 não sofreram grandes alterações em seu comportamento e o limitante de área trincada reduziu para $10 \%$, condizente com os pavimentos de Concessões Rodoviárias Brasileiras. Para a M10 - menor dano - o Nf foi determinado em 180 meses, admitindo-se, mesmo sem ter alcançado, os $10 \%$ de área trincada. Para as outras estruturas, o $\mathrm{Nf}$ foi calculado e os resultados estão expostos na Tabela 8.

Tabela 8: Custos das estruturas ao longo da vida útil.

\begin{tabular}{|c|c|c|c|}
\hline Mistura & $\mathrm{R} \$ / \mathrm{m}^{3}$ & $\mathrm{Nf}$ & $\mathrm{R} \$ / \mathrm{Nf}$ \\
\hline MO & $\mathrm{R} \$ \quad 676,94$ & $2,50 E+05$ & $\mathrm{R} \$ \quad 0,0027078$ \\
\hline M10 & 674,91 & $8,11 E+07$ & 0,0000083 \\
\hline M20 & 670,20 & $7,19 E+07$ & 0,0000093 \\
\hline M30 & 635,82 & $1,67 E+05$ & 0,0038149 \\
\hline
\end{tabular}

Quando se avalia o R\$̦/Nf, nota-se que o ideal é a M10, seguida da M20, M0 e M30. Isto permite concluir que projetos de estruturas de pavimentos com revestimentos asfálticos reciclados à quente necessitam passar por esta análise, pois o RAP influencia no comportamento das misturas.

\section{CONCLUSÕES}

Verifica-se que o beneficiamento do RAP é relevante para o bom desenvolvimento da usinagem e aplicação das misturas, visto que o peneiramento de melhor qualidade não interferiu tanto na usinagem quanto na qualidade das misturas. O processo de implementação de RAP na usina foi satisfatório.

No controle tecnológico realizado percebeu-se algumas inconsistências quanto ao teor de ligante asfáltico final e as granulometrias das misturas. Isto pode estar relacionado diretamente ao beneficiamento do RAP, a falta de calibração da usina e incorporação de agregados com descontinuidades de granulometria e umidades ou possíveis contaminações.

Não se pode concluir genericamente a respeito do comportamento das misturas conforme o teor de RAP inserido, o que pode ser devido ao fato dos diferentes teores inseridos e finais de ligante asfáltico encontrados, o desconhecimento da eficiência do misturador com entrada de RAP a frio, bem como os baixos e pequenos intervalos entre os teores de material fresado incorporados. Todavia é claro que a mistura mantém os padrões de misturas convencionais.

Ademais, uma análise de fadiga aliada aos custos foi realizada para verificação da viabilidade de aplicação da técnica por completo. Verificou-se que a M30 teve menor custo unitário por $\mathrm{m}^{3}$, mas quando se avalia este custo estendido na vida de fadiga das misturas, a M10 deve ser a escolhida.

\section{REFERÊNCIAS}

ARRA. Asphalt Recycling and Reclaiming Association. Pavement Recycling Guidelines for State and Local Governments Participant's Reference Book. U.S. Department of Transportation, FHWA-SA-98-042. Washington: ARRA, 1997.
AASHTO. American Association of State Highway and Transportation Officials. Standard Specifications for SUPERPAVE Volumetric Mix Design. AASHTO MP2, Washington: AASHTO, 2001.

BOEIRA, F. D.. Estudo da rigidez, da deformação 
permanente e da fadiga de misturas asfálticas com ligantes convencionais e modificados. Tese (Doutorado em Engenharia Civil) - Universidade Federal de Santa Maria, Santa Maria, 2018.

BOHN, K. A.. Avaliação de Misturas Asfálticas Recicladas Mornas com uso de Ligantes Convencional e Modificado por Polímero. Revista Transportes, Rio de Janeiro, v.27, n.4, 2020. DOI: http://doi.org/10.14295/transportes.v27i4.1740

CENTOFANTE, R.. Avaliação do comportamento de misturas asfálticas recicladas à quente com inserção de material fresado. Revista Matéria, Rio de Janeiro, v.23, n.3, 2018. DOI: http://doi.org/10.1590/s1517-707620180003.0512

CNT. Confederação Nacional de Transportes. Transporte rodoviário: desempenho do setor, infraestrutura e investimentos. Brasília: CNT, 2018.

DNER. Departamento Nacional de Estradas de Rodagem. PRO 13: Coleta de amostra de misturas betuminosas para pavimentação. Rio de Janeiro: DNER, 1994.

DNER. Departamento Nacional de Estradas de Rodagem. ME 043/95: Misturas Betuminosas à quente - Ensaio Marshall. Rio de Janeiro: DNER, 1995.

DNER. Departamento Nacional de Estradas de Rodagem. ME 053/94: Misturas Betuminosas - Percentagem de betume. Rio de Janeiro: DNER, 1994.

DNER. Departamento Nacional de Estradas de Rodagem. ES 385/99: Pavimentação - concreto asfáltico com asfalto polímero. Rio de Janeiro: DNER, 1999.

DNER. Departamento Nacional de Estradas de Rodagem. ES 386/99: Pavimentação - Pré-misturado à quente com asfalto polímero - camada porosa de atrito. Rio de Janeiro: DNER, 1999.

DNIT. Departamento Nacional de Infraestrutura de Transportes. ES 031: Pavimentos Flexíveis - Concreto Asfáltico. Rio de Janeiro: DNIT, 2006.

DNIT. Departamento Nacional de Infraestrutura de Transportes. ES 033: Pavimentos flexíveis - Concreto asfáltico reciclado à quente na usina. Rio de Janeiro: DNIT, 2005.

DNIT. Departamento Nacional de Infraestrutura de Transportes. ME 135/2018: Pavimentação asfáltica Mistura asfálticas - Determinação do módulo de resiliência Método de Ensaio. Rio de Janeiro: DNIT, 2018.

DNIT. Departamento Nacional de Infraestrutura de Transportes. ME 136: Pavimentação asfáltica - Misturas asfálticas - Determinação da resistência à tração por compressão diametral. Rio de Janeiro DNIT, 2018

DNIT. Departamento Nacional de Infraestrutura de Transportes. ME 180: Misturas asfálticas - Determinação do dano por umidade induzida. Rio de Janeiro DNIT, 2010.

DNIT. Departamento Nacional de Infraestrutura de Transportes. IPR 720: Manual de Restauração de Pavimentos Asfálticos. 2 ed. Rio de Janeiro DNIT, 2006.
FHWA. Federal Highway Administration. Reclaimed Asphalt Pavement in Asphalt Mixtures: State of the Practice. U.S. Department of Transportation, FHWA-HRT-11-021. Washington: FHWA, 2011.

HUANG, B.; LI, G.; VUKOSAVLJEVIC, D.; SHU, X.; EGAN, B. K. Laboratory Investigation of Mixing Hot-Mix Asphalt with Reclaimed Asphalt Pavement. Transportation Research Record: Journal of the Transportation Research Board, Washington, v.1929, n.1, p.37-45, 2005. DOI: http://doi.org/10.1177/0361198105192900105

LUZZI, F. C.. Adaptação de Usina para Reciclagem à quente e Avaliação Laboratorial das Misturas Asfálticas Produzidas. Dissertação (Mestrado em Engenharia Civil) - Universidade Federal de Santa Maria, Santa Maria, 2019.

NASCIMENTO, L. A.. Nova abordagem da dosagem de misturas asfálticas densas com uso do compactador giratório e foco na deformação permanente. Dissertação (Mestrado) - Universidade Federal do Rio de Janeiro, Rio de Janeiro, 2008.

NASCIMENTO, L. A. H.. Implementation and Validation of the Viscoelastic Continuum Damage Theory for Asphalt Mixture and Pavement Analysis in Brazil. Thesis (Doctorate Civil Engineering) - North Carolina State University, Raleigh, 2015.

NAPA. National Asphalt Pavement Association. Recycling Hot Mix Asphalt Pavements. Information Series 123. Lanham: NAPA, 1996

SABOURI, M. A., KIM, Y. R.. Development of a failure criterion for asphalt mixtures under different modes of fatigue loading. Transportation Research Record: Journal of the Transportation Research Board, v.2447, p.117-125, 2014. DOI: http://doi.org/10.3141/2447-13

SCHUSTER, S. L.. Estudo do comportamento à fadiga de misturas asfálticas aplicadas em campo por meio da teoria viscoelástica de dano contínuo. Dissertação (Mestrado em Engenharia Civil) - Universidade Federal de Santa Maria, Santa Maria, 2018.

SUZUKI, K.. Avaliação do percentual de material fresado em misturas asfálticas recicladas à quente e aplicação em projetos de restauração de pavimentos. Dissertação (Mestrado em Ciências) - Escola Politécnica da Universidade de São Paulo, São Paulo, 2018.

WEST, R. C.. Reclaimed Asphalt Pavement Management: Best Practices. NCAT Report. Auburn University, 2010.

WEST, R.; KVASNAK, A.; TRAN, N.; POWELL, B.; TURNER, P.. Testing of Moderate and High Reclaimed Asphalt Pavement Content Mixes. Transportation Research Record: Journal of the Transportation Research Board, v.2126, n.1, 2009. DOI: http://doi.org/10.3141/2126-12

ZAUMANIS, M. MALLICK, R. B. FRANK, R.. 100\% Recycled hot mix asphalt: A review and analysis. Resources, Conservation and Recycling, v.92, p.230-245, 2014. DOI: http://doi.org/10.1016/j.resconrec.2014.07.007

A CBPC - Companhia Brasileira de Produção Científica (CNPJ: 11.221.422/0001-03) detém os direitos materiais desta publicação. Os direitos referem-se à publicação do trabalho em qualquer parte do mundo, incluindo os direitos às renovações, expansões e disseminações da contribuição, bem como outros direitos subsidiários. Todos os trabalhos publicados eletronicamente poderão posteriormente ser publicados em coletâneas impressas sob coordenação da Sustenere Publishing, da Companhia Brasileira de Produção Científica e seus parceiros autorizados. Os (as) autores (as) preservam os direitos autorais, mas não têm permissão para a publicação da contribuição em outro meio, impresso ou digital, em português ou em tradução. 